\title{
Classified Marketplace
}

\section{INFECTION CONTROL COORDINATOR}

Woman's Hospital is currently seeking a full-time Infection Control Coordinator. Qualifications include Registered Nurse, previous experience in Infection Control, and certification in Infection Control. Job responsibilities inherent with this position will be the administration of the Infection Control program. Computer skills are a must along with outstanding communication skills.

Along with our extraordinary work environment, we also offer an excellent benefit package including health insurance, long-tern disability, life insurance and near site child care and fitness center.

For more information or to apply, please submit resume with salary requirements to:

Linda B. Lee, RN, BSN

Recruiting Coordinator

Woman's Hospital

9050 Airline Highway

Baton Rouge, LA 70815

(504)924-8143

EQUAL OPPORTUNITY EMPLOYER

\section{INFECTION CONTROL COORDINATOR}

Infection Control Coordinator needed to direct surveillance, education and policy development. Must be familiar with JCAHO standards and TB requirements, Bachelors
Degree in Nursing with 3-5 years experience in Infection Control required. Masters degree preferred. Candidates may be subject to random drug screening. Interested and qualified candidates should submit a resume to:

$$
\begin{gathered}
\text { Clement J. Zablocki } \\
\text { VA Medical Center } \\
5000 \text { W. National Avenue } \\
\text { Milwaukee, WI } 53295
\end{gathered}
$$$$
\text { (414) } 382-5310
$$

The Clement J. Zablocki VA Medical Center is an Equal Opportunity/Affirmative Action Employer. Women, minorities, and individuals with disabilities are encouraged to apply.

\section{FOR SALE}

\section{END LATEX EXPOSURE}

NONLATEX DISPOSABLE GLOVES: Tactile sensitivity, manual dexterity equal to or better than latex gloves. For a FREE sample call:

$$
\begin{aligned}
& \text { TRU-BLU SUPPLY } \\
& \text { 800-968-5460 } \\
& \text { FAX (501) } 968-5224
\end{aligned}
$$

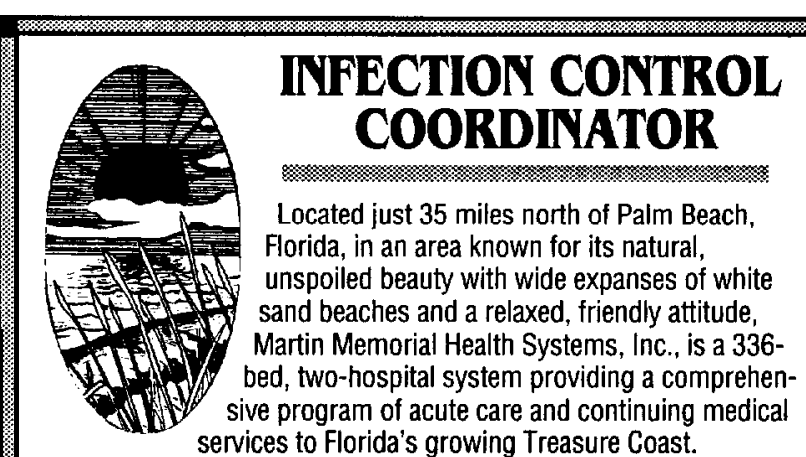

You can become a key member of our Quality Assessment Department as an Infection Control Practitioner. You will coordinate our Infection Control Program, providing vital information to staff, physicians and patients, and act as an interdepartmental resource in the development of all Infection Control activities. A BS degree in a healthcare field and a proven track record in the process of JCAHO accreditation are required. $\mathrm{CIC}$ certification preferred.

Along with an outstanding compensation and benefits package, you'll enjoy the rustic charm of our beautiful seaside location which offers great weather, affordable cost-of-living, no state income tax, fine schools, and many exciting leisure-time options. For immediate consideration, call or write to:

Victoria Paskaly,

Director of Human

Resources, Martin

Memorial Medical Center.

P.0. Box 9010, Stuart, FL 34995. (407) 288-5837. An equal opportunity employer.

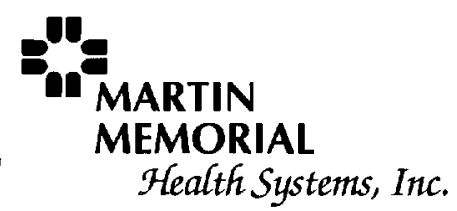

The Natural Choice.

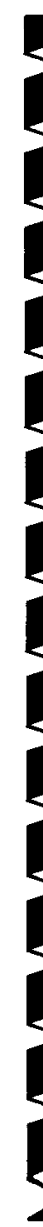

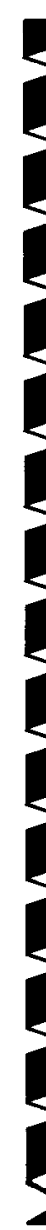

\section{EPIDEMIOLOGY/ ENVIRONMENTAL MANAGER}

Winter Haven Hospital, a progressive, 550-bed, private community hospital located in Central Florida, seeks an experienced professional to manage its recognized infection control program. Our program is strengthened by information support from our Quality Assurance/ Utilization Review Department.

You will be responsible for enhancing infection control intervention policy development and educational planning as well asassimilating and analyzing data. We will also rely on you for close collaboration with our Administrative, Patient Care, Educational and Laboratory Services and the association of an Infectious Disease Physician Clinical Director help to integrate the program into all aspects of hospital practice and planning.

Our selected candidate will have 2-3 years experience as an infection control practitioner. Excellent creative skills are essential. Certification is preferred. A bachelor's degree in nursing or allied science is required.

We offer an attractive salary/benefits package and ample opportunity for professional growth. You will also enjoy the sun-filled lifestyle and diverse range of recreational activities of Winter Haven. Central to both coasts, the city is just minutes from Orlando and Tampa. For consideration, please send resume or contact: Kit Threlkel, RN, Professional Recruiter, WINTER HAVEN HOSPITAL, 200 Avenue F, N.E., Winter Haven, FL 33881. 1-800937.1725. EOE.

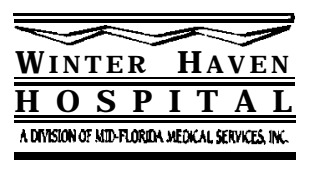



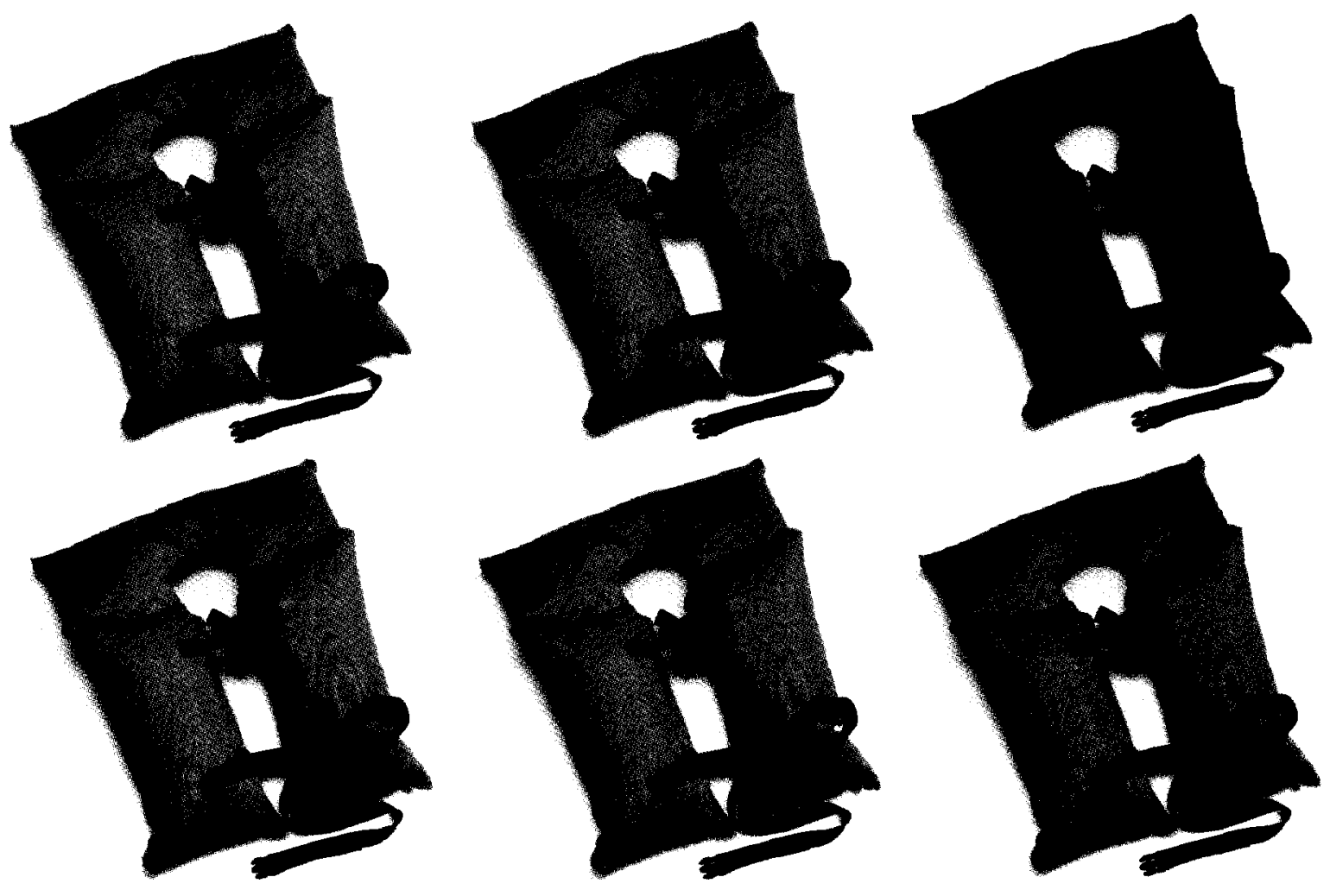

\section{If the blue one protected 4 times better, would you use it?}

When a risk arises, it's not a question of if you should protect yourself but how to best protect yourself.

With costly central venous catheter-related infections occurring at a rate of $3 \%$ to $12 \%$, and an associated mortality rate of $20 \%,{ }^{1}$ the risks are real.

ARROWg'tard Blue" is your best defense against infection.

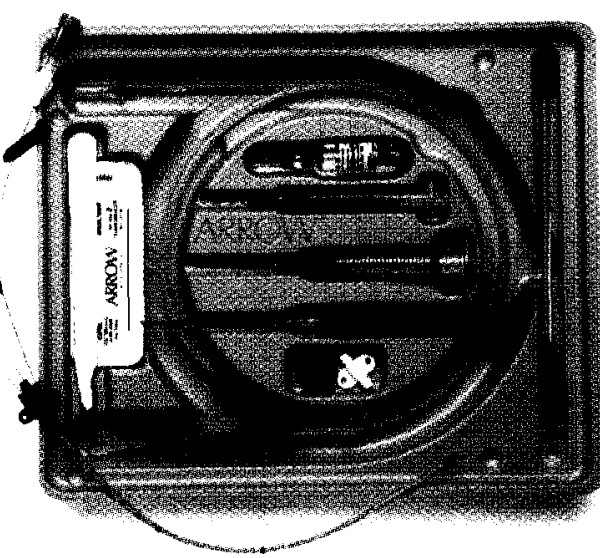

CVC catheters with the built-in protection of ARROWg'tard Blue" "are up to $80 \%$ less likely to develop bacteremia than unprotected catheters! So you can save up to $80 \%$ of your CVC patients from the risk of a catheter-related bloodstream infection. And you can save your hospital from the expense of $\$ 7,000$ per infection.

To learn about all the benefits of ARROWg'ard Blue" catheters, contact your Arrow representative or call $1800523-8446$

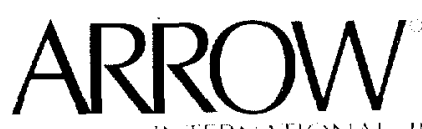

